\title{
Work-Related Musculoskeletal Symptoms in Otorhinolaryngology-Head and Neck Surgery Residents
}

"Abdulmajeed Bin Dahmash, ${ }^{1}$ Feras Alkholaiwi, ${ }^{2}$ Abdussalam Alahmari, ${ }^{3}$ Asem M. Shadid, ${ }^{1}$ Abdulrahman M. Alharbi, ${ }^{1}$ Omair Al Hussain ${ }^{2}$

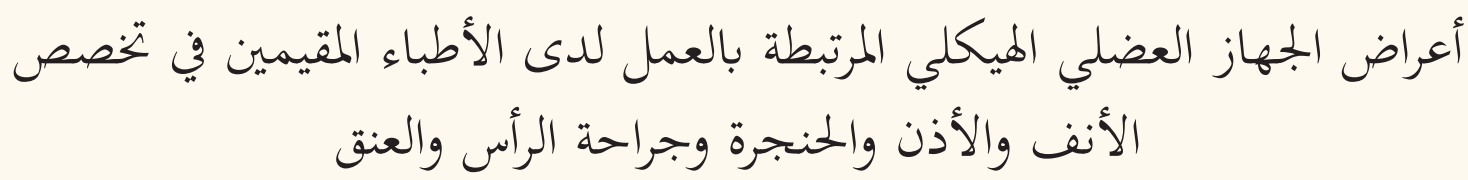

عبد الهجيد بن دهمش، فراس الخليوي، عبدالسلام الاحمري، عاصم مصطفى شديد، عبدالرحمن مشعل الحربي، عُمير الحسين

ABSTRACT: Objectives: Work-related musculoskeletal disorders in Saudi Arabia are not often reported in the literature. This study aimed to identify musculoskeletal symptoms among otorhinolaryngology residents in Saudi Arabia. Methods: This cross-sectional survey-based study was conducted in May 2018 and included residents registered in the Saudi Otorhinolaryngology-Head and Neck Surgery Board Training programme, Riyadh, Saudi Arabia. The Nordic Musculoskeletal Questionnaire was used to assess musculoskeletal symptoms in addition to demographic and occupational factors, including operating position and the average number of operating hours. Results: A total of 45 residents (response rate: 68.2\%) completed the survey, including 33 males (73.3\%) and 12 females (26.7\%). Most residents (91.1\%) reported at least one musculoskeletal symptom. The most commonly reported musculoskeletal over the previous 12 months were shoulder complaints (64.4\%) followed by neck complaints (60\%). In the short term (i.e. within seven days preceding the survey), neck complaints were more common than shoulder complaints (28.9\% versus $20 \%$ ). Lower back complaints were the most common cause of activity limitation (24.4\%) followed by shoulder complaints (13.3\%), while those with neck complaints reported it as a cause for visiting a physician (8.9\%). Hip and thigh complaints were significantly more frequent among residents with operation times of eight hours or more compared to those who operating for less than eight hours $(42.9 \%$ versus $5.9 \%$; $P=0.021)$. Conclusion: A high incidence of shoulder, neck and lower back complaints was found in this study. Residency is an ideal time in an otorhinolaryngologist's career to implement programmes in ergonomic best practices before bad habits are developed.

Keywords: Otorhinolaryngology; Musculoskeletal Abnormalities; Symptoms and Signs; Workplace; Ergonomics; Saudi Arabia.

الملخص: الهدف: لا يتم في كثير من الأحيان ذكر الاضطرابـات العضلية الهيكلية المرتبطة بالعمل في المملكة العربية السعودية في الأدبيات.

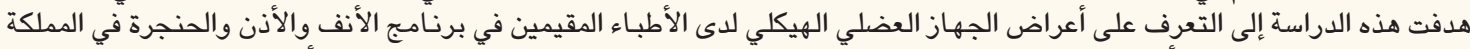

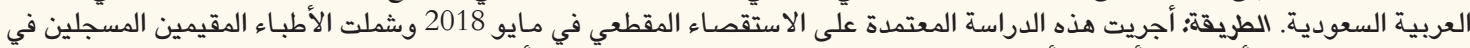

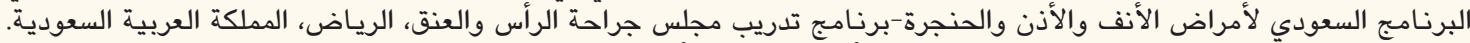

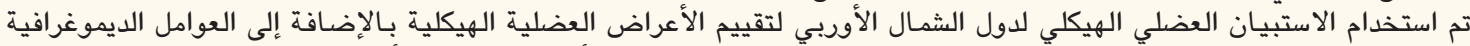

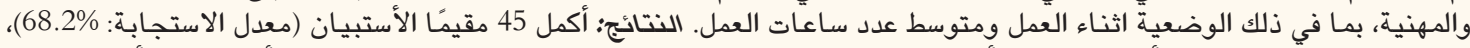

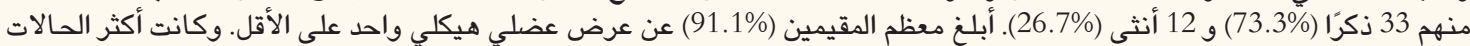

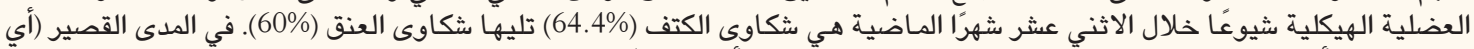

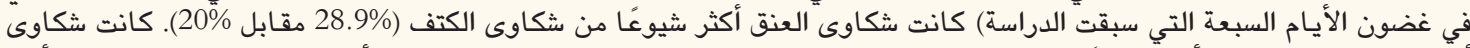

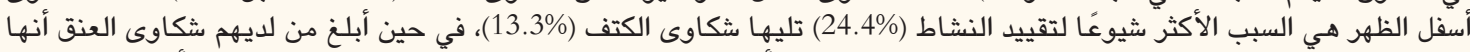

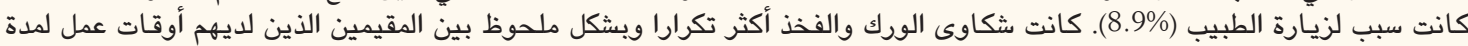

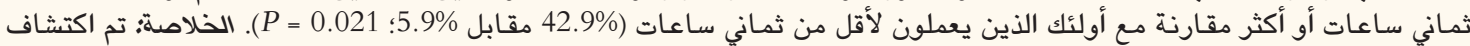

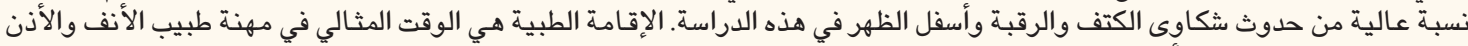

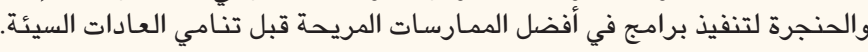

الكلمات المفتاحية: طب الأنف والأذن والحنجرة؛ الأضطرابـات العضلية الهيكلية؛ الأعراض والعلامات؛ ككان العمل؛ الممارسات المريحة؛ المملكة العربية السعودية.

\section{Advances IN KNOWLedge}

Otorhinolaryngology residents are susceptible to work-related musculoskeletal disorders.

It is important to develop awareness of good ergonomic practices among physicians to create better workplace ergonomics. Along with 
adequately spaced breaks, such a practice can translate into better surgical performance for otorhinolaryngology residents.

\section{Application to Patient Care}

There is a relationship between surgeon fatigue and perceived medical errors. This relationship, in conjunction with the findings of this study, indicate the importance of implementing good ergonomic practices, and of practitioners learning to adopt acceptable postures during surgery and taking breaks between procedures.

$\mathrm{W}$ ORK-RELATED MUSCULOSKELETAL DISorders (WRMSDs) are often reported by healthcare professionals, including nurses and dentists. ${ }^{1,2}$ Such injuries are often the leading cause of premature retirement. ${ }^{3}$ For surgeons, the prevalence rate of subjective musculoskeletal complaints ranges between $17.5-50.0 \%$ for neck and upper and lower back pain. ${ }^{1}$ Orthopaedic surgeons, obstetricians and gynaecologists have also been found to show an incidence of shoulder, neck and back pain. ${ }^{4-6}$

Surgeons and residents in surgical specialties are at high risk for developing WRMSDs due to the demands of surgery during which they remain in fixed postures for long hours. ${ }^{7}$ Over longer periods of time, exposure to biomechanical stressors may also intensify musculoskeletal injuries in the workplace. ${ }^{8}$ During an operation, surgeons often assume postures such as head-bent and back-bent, making them highly susceptible to physical discomfort. ${ }^{9}$ Laparoscopic procedures limit body movement and demand a static upright body posture, contributing to numerous ergonomic risk factors. ${ }^{10}$ Furthermore, repetitive wrist motions during surgery and static neck postures can aggravate musculoskeletal issues. ${ }^{11,12}$

WRMSDs among otorhinolaryngology-head and neck surgery (ORL-HNS) residents are not often reported in the literature. In a study on work postures of operating room staff, Kant et al. compared general surgeons and ORL-HNS surgeons and reported that ORL-HNS had better working posture than general surgeons, but both had poor work posture during more than $80 \%$ of their operating time. ${ }^{13}$ Surgeons performing endoscopic sinus surgery suffer from the physical constraints of these surgeries, while laryngologists working without arm support are at risk of shoulder and back strains. ${ }^{1,14}$ As per surveys in the USA, $62 \%$ of paediatric otorhinolaryngologists experience pain and discomfort attributed to their work. $^{15,16}$

Few studies have examined musculoskeletal symptoms among surgeons in various specialties. Therefore, this study aimed to identify the prevalence of work-related musculoskeletal symptoms among ORL-HNS residents. In addition, this study will evaluate whether demographic factors such as age and gender, as well as occupational/ergonomic factors including operating position and the average number of operating hours, were significantly associated with musculoskeletal complaints.

\section{Methods}

This cross-sectional survey-based study was conducted in May 2018. All 66 residents registered in the Saudi Otorhinolaryngology-Head and Neck Surgery Board Training programme, Riyadh, Saudi Arabia from postgraduate year two to five were approached to participate. Residents in postgraduate year one were excluded as they had received little otorhinolaryngology training and were rotating in other specialties. The questionnaire was distributed by a senior resident during the weekly academic activities with the Saudi ORL-HNS Board Training programme.

The survey was adapted from the previously validated Nordic Musculoskeletal Questionnaire (NMQ). ${ }^{17}$ The first part of this two-part survey included items on gender, age, height, weight, postgraduate year, average hours in the operating room/week, handedness, average hours of sleep per day and amount of exercise per week. The operating position was assessed using a self-reported five-point Likert scale ranging from 1 'sitting all the time' to 5 'standing all the time.' The second section inquired about musculoskeletal symptoms in nine anatomical regions according to the NMQ including the neck, shoulders, elbows, wrists/hands, upper back, lower back, hips/thighs, knees and ankles/feet. A slight modification was made to the questionnaire; participants were asked whether they had long-term (i.e. during the 12 months preceding the survey) and recent (i.e. seven days preceding the survey) complaints in each anatomic region. The questionnaire also assessed whether participants had visited a physician for these problems and whether they had been prevented from carrying out normal activities during the last 12 months due to these complaints.

Statistical analysis was performed using Statistical Package for Social Sciences (SPSS), Version 24.0 (IBM Corp., Armonk, New York, USA) and RStudio, Version 1.3 (RStudio, Inc., Boston, Massachusetts, USA). Categorical data such as gender and age were presented as frequencies and percentages while continuous data were presented as means and standard deviation. In addition, the prevalence of complaints per 
Table 1: Characteristics of residents in the Otorhinolaryngology-Head and Neck Surgery Board Training programme, Riyadh, Saudi Arabia $(\mathrm{N}=45)$

\begin{tabular}{|c|c|}
\hline Age Characteristic & n (\%) \\
\hline \multicolumn{2}{|l|}{ Age Age in years } \\
\hline $25-27$ & $16(35.6)$ \\
\hline $28-30$ & $29(64.4)$ \\
\hline \multicolumn{2}{|l|}{ Gender } \\
\hline Female & $12(26.7)$ \\
\hline Male & $33(73.3)$ \\
\hline \multicolumn{2}{|l|}{ Marital status } \\
\hline Married & $21(46.7)$ \\
\hline Unmarried & $24(53.3)$ \\
\hline \multicolumn{2}{|l|}{ Residency level } \\
\hline PGY 2 & $11(24.4)$ \\
\hline PGY 3 & $11(24.4)$ \\
\hline PGY 4 & $15(33.3)$ \\
\hline PGY 5 & $8(17.8)$ \\
\hline \multicolumn{2}{|l|}{ Exercise in days per week } \\
\hline 0 & $18(40.0)$ \\
\hline 1 & $8(17.8)$ \\
\hline 2 & $10(22.2)$ \\
\hline 3 & $9(20)$ \\
\hline \multicolumn{2}{|l|}{ Average hours of sleep per day } \\
\hline 6 & $12(26.7)$ \\
\hline 7 & $22(48.9)$ \\
\hline 8 & $8(17.8)$ \\
\hline$\geq 9$ & $3(6.7)$ \\
\hline \multicolumn{2}{|l|}{ Operating position } \\
\hline Sitting all the time & $1(2.2)$ \\
\hline Sitting most of the time & $8(17.8)$ \\
\hline Equally standing and sitting & $13(28.9)$ \\
\hline Standing most of the time & $16(35.6)$ \\
\hline Standing all the time & $7(15.6)$ \\
\hline \multicolumn{2}{|l|}{ Dominant hand } \\
\hline Left & $5(11.1)$ \\
\hline Right & $40(88.9)$ \\
\hline Mean weight in $\mathrm{kg} \pm \mathrm{SD}$ & $73.69 \pm 15.20$ \\
\hline Mean height in $\mathrm{cm} \pm \mathrm{SD}$ & $170.78 \pm 8.13$ \\
\hline Mean BMI in $\mathrm{kg} / \mathrm{m}^{2} \pm \mathrm{SD}$ & $25.10 \pm 3.77$ \\
\hline Mean number of operations per week \pm SD & $2.31 \pm 1.33$ \\
\hline Mean hours in operating room per week \pm SD & $8.00 \pm 3.6$ \\
\hline
\end{tabular}

$P G Y=$ programme year $\mathrm{kg}=$ kilogram $\mathrm{SD}=$ standard deviation; $\mathrm{cm}=$ centimetre $; B M I=$ body mass index

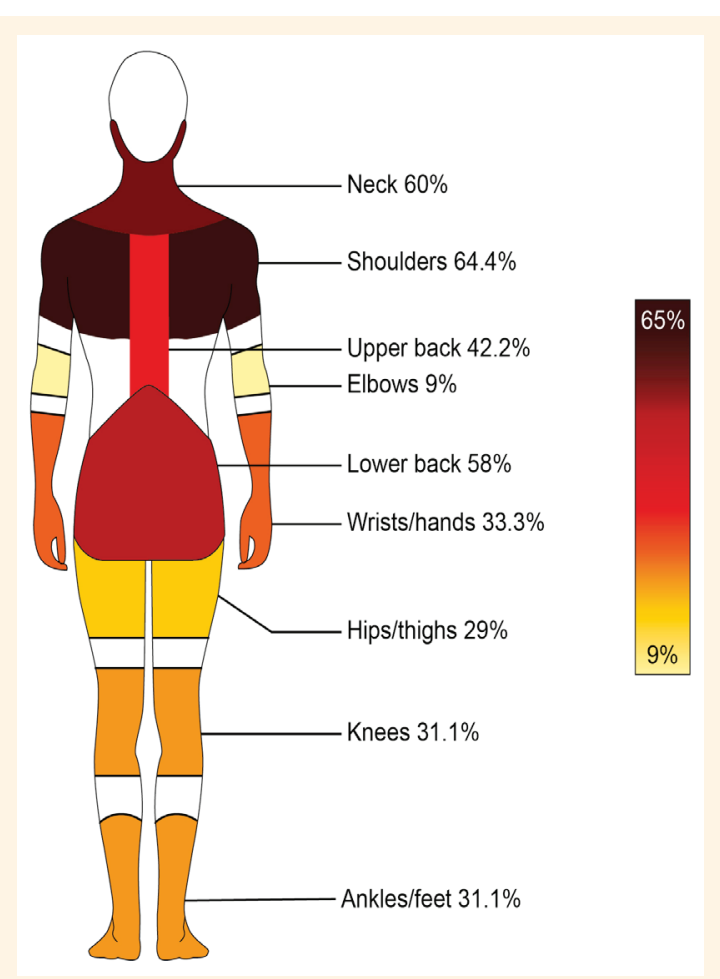

Figure 1: Anatomical illustration of each musculoskeletal complaint by anatomical region in the 12 months preceding the survey.

each anatomic region was reported as a frequency and percentage. Bar plots were also used to visualise results. A Chi-square test was performed to assess whether age, gender, operating position or the average number of operating hours were significantly associated with musculoskeletal complaints in any of the nine anatomic regions. The level of statistical significance was set at 0.05 .

Institutional review board (IRB) approval was obtained from the Medical Research Unit of the College of Medicine at Imam Mohammad ibn Saud Islamic University, Riyadh, Saudi Arabia (IRB code: 0030/03/2018-48). The purpose of the study was explained to the residents before obtaining informed consent.

\section{Results}

A total of 45 residents (response rate: 68.2\%) completed the survey. Most participants were 28-30 years old (64.4\%) and the majority of participants were male (73.3\%) [Table 1].

Only four participants (8.9\%) did not report any musculoskeletal discomfort. The remaining 41 participants (91.1\%) reported at least one musculoskeletal complaint. Shoulder complaints were most commonly reported within the past year (64.4\%) followed by complaints associated with the neck (60\%) [Figure 1]. 


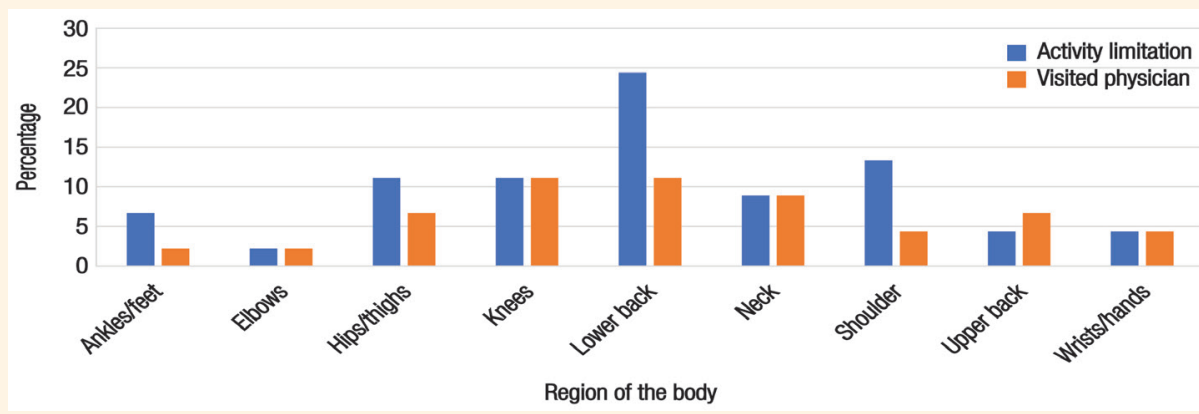

Figure 2: Impact of musculoskeletal complaints of residents $(\mathrm{N}=45)$.

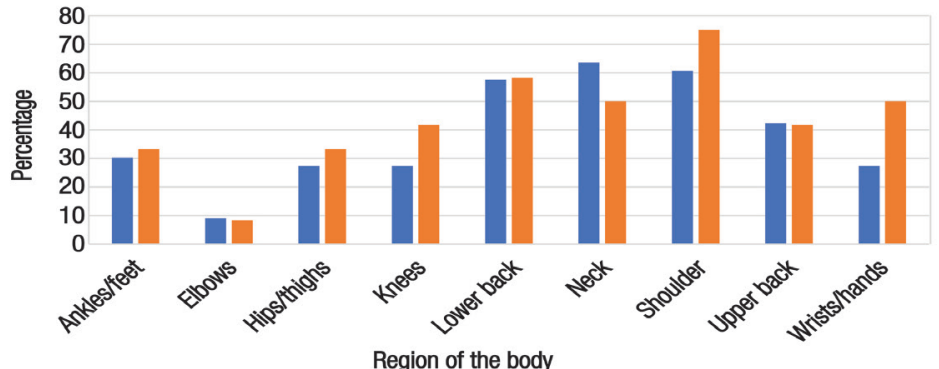

Figure 3: Musculoskeletal complaints of residents stratified by gender.

Table 2: Association of gender and age of residents with musculoskeletal complaints within the 12 months preceding the study $(\mathrm{N}=45)$

\begin{tabular}{|c|c|c|c|c|c|c|}
\hline \multirow[t]{3}{*}{ Region of the body } & & & \multirow[t]{3}{*}{$P$ value } & & & \multirow[t]{3}{*}{$P$ value* } \\
\hline & \multicolumn{2}{|c|}{ Gender } & & \multicolumn{2}{|c|}{ Age in years } & \\
\hline & Female $(n=12)$ & Male $(\mathbf{n}=33)$ & & $25-27(\mathrm{n}=16)$ & $28-30(n=29)$ & \\
\hline Neck & $6(50.0)$ & $21(63.6)$ & 0.630 & $8(50.0)$ & $19(65.5)$ & 0.484 \\
\hline Shoulder & $9(75.0)$ & $20(60.6)$ & 0.589 & $10(62.5)$ & $19(65.5)$ & 1.000 \\
\hline Upper back & $5(41.7)$ & $14(42.4)$ & 1.000 & $5(31.2)$ & $14(48.3)$ & 0.429 \\
\hline Elbows & $1(8.3)$ & $3(9.1)$ & 1.000 & $1(6.2)$ & $3(10.3)$ & 1.000 \\
\hline Wrists/hands & $6(50.0)$ & $9(27.3)$ & 0.283 & $8(50.0)$ & $7(24.1)$ & 0.152 \\
\hline Lower back & $7(58.3)$ & $19(57.6)$ & 1.000 & $9(56.2)$ & $17(58.6)$ & 1.000 \\
\hline Hips/thighs & $4(33.3)$ & $9(27.3)$ & 0.980 & $6(37.5)$ & $7(24.1)$ & 0.546 \\
\hline Knees & $5(41.7)$ & $9(27.3)$ & 0.577 & $6(37.5)$ & $8(27.6)$ & 0.725 \\
\hline Ankles/feet & $4(33.3)$ & $10(30.3)$ & 1.000 & $5(31.2)$ & $9(31.0)$ & 1.000 \\
\hline
\end{tabular}

*Using Chi-square test.

However, neck complaints were more common than shoulder complaints within the week preceding the survey (28.9\% versus 20\%). Elbow complaints (9\%) were the least commonly reported complaint.

Lower back complaints were the most common cause of activity limitation (24.4\%) followed by shoulder complaints (13.3\%). Lower back complaints were the most common reason for visiting a physician (11.1\%) [Figure 2].

Shoulder complaints were most commonly reported by females during 12 months preceding the survey (75\%) while neck complaints were the most commonly reported musculoskeletal complaints among males (63.6\%). Wrist/hand complaints were more frequently reported by females than males ( $50 \%$ versus 27.3\%). The remaining musculoskeletal complaints were almost equally prevalent in males and females except for shoulder complaints, which were more common in females than males (75\% versus 60.6\%). [Figure 3].

No statistically significant association was found between age and gender and the prevalence of 
Table 3: Association of position during operation and operating hours with musculoskeletal complaints of residents within the 12 months preceding the survey $(\mathrm{N}=45)$

\begin{tabular}{|c|c|c|c|c|c|c|}
\hline \multirow[t]{3}{*}{ Region of the body } & & & \multirow[t]{3}{*}{$P$ value* } & \multicolumn{2}{|c|}{ n (\%) } & \multirow[t]{3}{*}{$P$ value } \\
\hline & \multicolumn{2}{|c|}{ Operating position } & & \multicolumn{2}{|c|}{ Operating hours per week } & \\
\hline & $\begin{array}{l}\text { Sitting or sitting } \\
\text { and standing } \\
(\mathbf{n}=22)\end{array}$ & $\begin{array}{c}\text { Standing } \\
(\mathbf{n}=23)\end{array}$ & & $\begin{array}{c}<8 \text { hours } \\
(\mathrm{n}=17)\end{array}$ & $\begin{array}{c}\geq 8 \text { hours } \\
(n=28)\end{array}$ & \\
\hline Neck & $11(50.0)$ & $16(69.6)$ & 0.301 & $8(47.1)$ & $19(67.9)$ & 0.286 \\
\hline Shoulder & $13(59.1)$ & $16(69.6)$ & 0.673 & $8(47.1)$ & $21(75.0)$ & 0.115 \\
\hline Upper back & $8(36.4)$ & $11(47.8)$ & 0.634 & 4. (23.5) & $15(53.6)$ & 0.096 \\
\hline Elbows & $4(18.2)$ & $0(0.0)$ & 0.106 & $2(11.8)$ & $2(7.1)$ & 1.000 \\
\hline Wrists/hands & $7(31.8)$ & $8(34.8)$ & 1.000 & $5(29.4)$ & $10(35.7)$ & 0.913 \\
\hline Lower back & $12(54.5)$ & $14(60.9)$ & 0.899 & $7(41.2)$ & $19(67.9)$ & 0.148 \\
\hline Hips/thighs & $4(18.2)$ & $9(39.1)$ & 0.222 & $1(5.9)$ & $12(42.9)$ & 0.021 \\
\hline Knees & $6(27.3)$ & $8(34.8)$ & 0.824 & $5(29.4)$ & $9(32.1)$ & 1.000 \\
\hline Ankles/feet & $4(18.2)$ & $10(43.5)$ & 0.131 & $4(23.5)$ & $10(35.7)$ & 0.600 \\
\hline
\end{tabular}

*Using Chi-square test.

musculoskeletal complaints [Table 2]. None of the complaints were significantly associated with body position during operating. However, the percentages were consistently higher in residents who spent most or all their time in a standing position [Table 3].

Hip/thigh complaints were positively and significantly correlated to the residents who operated for eight hours or more compared to residents who operated for less than eight hours (42.9\% versus 5.9\%; $P=0.021$ ). Upper back complaints were also more common among residents who operated for more than eight hours compared to those who operated less than eight hours but was not statistically significant (53.6\% versus $23.5 \% ; P=0.096$ ) [Table 3].

\section{Discussion}

The working hours of ORL-HNS practitioners involve prolonged standing, occasionally repetitive movements and the exertion of substantial forces on tissues. All these factors are associated with WRMSDs. ${ }^{13,18}$ Additionally, head and neck surgeries are associated with physical and movement constraints associated with operating table height and the posture and movements of surgeons and their assistants.

In the current study, a high percentage of workrelated musculoskeletal symptoms were found in ORL-HNS residents (91.1\%), which is similar to the rates reported by a Canadian study amongst ORLHNS surgeons (97\%). ${ }^{1}$ Cavanagh et al. reported a $62 \%$ incidence rate among paediatric otorhinolaryngologists and Vijendran et al. reported that $47.4 \%$ of included otorhinolaryngologists had musculoskeletal issues. ${ }^{12,15}$
In the present study, shoulder, neck and lower back complaints were most commonly reported which is similar to the survey conducted among 325 ear, nose and throat consultants in the UK, where the incidence of neck and back pain was reported to be $72 \%{ }^{19}$ In the current study females were more likely to report shoulder, wrist and hand complaints. A similar finding was also reported by Mirmohammadi et al., who found a significant difference in WRMSDs among female nurses compared to male nurses in Iran. ${ }^{20}$ However, the difference in complaints from male and female residents in the present study was not statistically significant, which could be due to the study's small sample size.

Shoulder, neck and lower back complaints were most commonly reported due to surgical practice and could be attributed to sustained postures, awkward positioning during surgery and taking inadequate breaks. Ergonomics associated with the height of the operating table, repetitive movements of the wrists as well as inadequate assistance could aggravate these issues. Back and neck pain are generally attributed to prolonged sitting in a stooped position as well as prolonged posture in a forward bending position that can fatigue the extensor musculature, aggravating myofascial pain in muscles of the lower back..$^{21,22}$

Previous studies indicate that a surgeon's physical position when operating is a risk factor for WRMSDs; however, the association between musculoskeletal symptoms with standing and sitting positions during surgery was insignificant in this study. ${ }^{12,23-25}$ In the present study, spending eight hours or more operating was a significant predictor of hip/thigh symptoms. 
Previous studies indicate that increased working hours is a risk factor for WRMSD. ${ }^{26}$ Lower back symptoms were the most common cause of activity limitation and seeking medical attention in this study. Furthermore, a study on orthopaedic residents showed that neck symptoms were the dominant cause of stopping surgeries. ${ }^{4}$

ORL-HNS and otorhinolaryngology residents are susceptible to WRMSD. It is important to create awareness among physicians of good ergonomic practice, including adopting acceptable postures during surgery and taking breaks between procedures. This practice is especially important considering the established relationship between surgeon fatigue and perceived medical error. ${ }^{27,28}$ Therefore, better ergonomics at the workplace along with adequately spaced breaks for otorhinolaryngology residents can translate into better surgical performance. Future research applying a validated ergonomic assessment like the Rapid Entire Body Assessment is highly recommended.

However, this study was subject to some limitations. The cross-sectional survey-based nature of the study is a limitation and future longitudinal studies on WRMSD are recommended. This study may also be prone to recall bias. Nevertheless, this study still provides beneficial information on the incidence of work-related musculoskeletal issues among ORLHNS residents in Saudi Arabia.

\section{Conclusion}

A high incidence of shoulder, neck and lower back complaints was found among ORL-HNS residents in Saudi Arabia. This study underscores the need for ergonomic considerations while planning resident workload as longer work hours were more likely to contribute to musculoskeletal complaints. Residency is an ideal time in an otorhinolaryngologist's career to implement teaching programmes around ergonomics to train for best ergonomic practices before bad habits form. Future studies among board-certified otorhinolaryngologists are recommended to identify the effect of musculoskeletal disorders on their longterm careers.

\section{CONFLICT OF INTEREST}

The authors declare no conflicts of interest.

\section{FUNDING}

No funding was received for this study.

\section{References}

1. Bolduc-Bégin J, Prince F, Christopoulos A, Ayad T. Work-related musculoskeletal symptoms amongst otolaryngologists and head and neck surgeons in Canada. Eur Arch Otorhinolaryngol 2018; 275:261-7. https://doi.org/10.1007/s00405-017-4787-1.

2. Szeto GP, Ho P, Ting AC, Poon JT, Cheng SW, Tsang RC. Workrelated musculoskeletal symptoms in surgeons. J Occup Rehabil 2009; 19:175-84. https://doi.org/10.1007/s10926-009-9176-1.

3. Milerad E, Ekenvall L. Symptoms of the neck and upper extremities in dentists. Scand J Work Environ Health 1990:129-34. https://doi.org/10.5271/sjweh.1807.

4. Knudsen ML, Ludewig PM, Braman JP. Musculoskeletal pain in resident orthopaedic surgeons: Results of a novel survey. Iowa Orthop J 2014; 34:190-6.

5. Dolan LM, Martin DH. Backache in gynaecologists. Occup Med (Lond) 2001; 51:433-8. https://doi.org/10.1093/occmed/51.7.433.

6. Yoong W, Sanchez-Crespo J, Rob J, Parikh M, Melendez J, Pillai R, et al. Sticks and stones may break my bones: Work-related orthopaedic injuries sustained during obstetrics and gynaecology training. J Obstet Gynaecol 2008; 28:478-81. https://doi.org/10.10 $80 / 01443610802091396$.

7. Rambabu T, Suneetha K. Prevalence of work related musculoskeletal disorders among physicians, surgeons and dentists: A comparative study. Ann Med Health Sci Res 2014; 4:578-82. https://doi.org/10.4103/2141-9248.139327.

8. Jain NB, Higgins LD, Losina E, Collins J, Blazar PE, Katz JN. Epidemiology of musculoskeletal upper extremity ambulatory surgery in the United States. BMC Musculoskelet Disord 2014; 15:4. https://doi.org/10.1186/1471-2474-15-4.

9. Berguer R, Rab GT, Abu-Ghaida H, Alarcon A, Chung J. A comparison of surgeons' posture during laparoscopic and open surgical procedures. Surg Endosc 1997; 11:139-42. https://doi.org/1 $0.1007 / \mathrm{s} 004649900316$

10. Karp SJ, Morris JPG. Blueprints surgery. 5th ed. Philadelphia, Pennsylvania, USA: Lippincott Williams \& Wilkins, 2008.

11. Esposito C, El Ghoneimi A, Yamataka A, Rothenberg S, Bailez $\mathrm{M}$, Ferro $\mathrm{M}$, et al. Work-related upper limb musculoskeletal disorders in paediatric laparoscopic surgery. A multicenter survey. J Pediatr Surg 2013; 48:1750-6. https://doi.org/10.1016/j.jped surg.2013.01.054.

12. Vijendren A, Yung M, Sanchez J, Duffield K. Occupational musculoskeletal pain amongst ENT surgeons - are we looking at the tip of an iceberg? J Laryngol Otol 2016; 130:490-6. https://doi.org/10.1017/S0022215116001006.

13. Kant IJ, de Jong LC, van Rijssen-Moll M, Borm PJ. A survey of static and dynamic work postures of operating room staff. Int Arch Occup Environ Health 1992; 63:423-8. https://doi.org/10.1 007/bf00386939.

14. Ayad T, Péloquin L, Prince F. Ergonomics in endoscopic sinus surgery: Systematic review of the literature. J Otolaryngol 2005; 34:333-40. https://doi.org/10.2310/7070.2005.34507.

15. Cavanagh J, Brake M, Kearns D, Hong P. Work environment discomfort and injury: An ergonomic survey study of the American Society of Pediatric Otolaryngology members. Am J Otolaryngol 2012;33:441-6. https://doi.org/10.1016/j.amjoto.2011.10.022.

16. Statham MM, Sukits AL, Redfern MS, Smith LJ, Sok JC, Rosen CA. Ergonomic analysis of microlaryngoscopy. Laryngoscope 2010; 120:297-305. https://doi.org/10.1002/lary.20686.

17. Kuorinka I, Jonsson B, Kilbom A, Vinterberg H, Biering-Sørensen F, Andersson G, et al. Standardised Nordic questionnaires for the analysis of musculoskeletal symptoms. Appl Ergon 1987; 18:233-7. https://doi.org/10.1016/0003-6870(87)90010-x.

18. Buckle PW, Devereux JJ. The nature of work-related neck and upper limb musculoskeletal disorders. Appl Ergon 2002; 33:207-17. https://doi.org/10.1016/S0003-6870(02)00014-5. 
19. Babar-Craig H, Banfield G, Knight J. Prevalence of back and neck pain amongst ENT consultants: National survey. J Laryngol Otol 2003; 117:979-82. https://doi.org/10.1258/002221503322683885

20. Mirmohammadi S, Yazdani J, Etemadinejad S, Asgarinejad H. A cross-sectional study on work-related musculoskeletal disorders and associated risk factors among hospital health cares. Procedia Manuf 2015; 3:4528-34. https://doi.org/10.1016/j.pro mfg.2015.07.468

21. Kumar VK, Kumar SP, Baliga MR. Prevalence of work-related musculoskeletal complaints among dentists in India: A national cross-sectional survey. Indian J Dent Res 2013; 24:428-38. https://doi.org/10.4103/0970-9290.118387.

22. Forde MS, Punnett L, Wegman DH. Pathomechanisms of workrelated musculoskeletal disorders: Conceptual issues. Ergonomics 2002; 45:619-30. https://doi.org/10.1080/00140130210 153487

23. Kazancioglu HO, Bereket MC, Ezirganli S, Ozsevik S, Sener I. Musculoskeletal complaints among oral and maxillofacial surgeons and dentists: A questionnaire study. Acta Odontol Scand 2013; 71:469-74. https://doi.org/10.3109/00016357.2012.696688.
24. Capone AC, Parikh PM, Gatti ME, Davidson BJ, Davison SP. Occupational injury in plastic surgeons. Plast Reconstr Surg 2010; 125:1555-61. https://doi.org/10.1097/PRS.0b013e3181d62a94.

25. Esposito C, Najmaldin A, Schier F, Yamataka A, Ferro M, Riccipetitoni G, et al. Work-related upper limb musculoskeletal disorders in pediatric minimally invasive surgery: A multicentric survey comparing laparoscopic and sils ergonomy. Pediatr Surg Int 2014; 30:395-9. https://doi.org/10.1007/s00383-013-3437-y.

26. Epstein S, Sparer EH, Tran BN, Ruan QZ, Dennerlein JT, Singhal D, et al. Prevalence of work-related musculoskeletal disorders among surgeons and interventionalists: A systematic review and metaanalysis. JAMA Surg 2018; 153:e174947. https://doi.org/10.10 01/jamasurg.2017.4947.

27. Gawande AA, Zinner MJ, Studdert DM, Brennan TA. Analysis of errors reported by surgeons at three teaching hospitals. Surgery 2003; 133:614-21. https://doi.org/10.1067/msy.2003.169.

28. Shanafelt TD, Bradley KA, Wipf JE, Back AL. Burnout and selfreported patient care in an internal medicine residency program. Ann Intern Med 2002; 136:358-67. https://doi.org/10.7326/00 03-4819-136-5-200203050-00008. 